\title{
Comparison of vaginal hysterectomy and laparoscopically assisted vaginal hysterectomy in women with benign uterine disease: a retrospective study
}

\author{
Sathiyakala Rajendran*, Suguna Srinivasan, Karnaboopathy R.
}

Department of Obstetrics and Gynecology, Shri Sathya Sai medical college and research institute, Ammapettai 603108 Kancheepuram, Tamilnadu, India

Received: 30 August 2016

Accepted: 28 September 2016

\section{*Correspondence:}

Dr. Sathiyakala Rajendran,

E-mail: sathya_jipmer@yahoo.co.in

Copyright: (c) the author(s), publisher and licensee Medip Academy. This is an open-access article distributed under the terms of the Creative Commons Attribution Non-Commercial License, which permits unrestricted non-commercial use, distribution, and reproduction in any medium, provided the original work is properly cited.

\section{ABSTRACT}

Background: Nowadays, there is a trend in favour of (laparoscopically assisted vaginal hysterectomy) LAVH even for patients in whom (vaginal hysterectomy) $\mathrm{VH}$ is feasible. Hence, this study is undertaken to compare the efficacy of LAVH and the traditional vaginal hysterectomy for the treatment of benign uterine disease and also to find out the advantage of LAVH over VH.

Methods: The study population consists of patients who had undergone hysterectomy for benign uterine disease excluding prolapse of uterus. Medical records of patients who had undergone vaginal hysterectomy (50) and LAVH (50) without any medical illness and without previous surgical history (except sterilisation) were collected. Age, parity, indication for hysterectomy, operative time, intra operative and postoperative complications and duration of hospital stay were noted and compared between the two groups.

Results: The mean operative time was significantly shorter in the VH group $(83.7 \mathrm{~min})$ than in the LAVH group $(128.7 \mathrm{~min})$ and the difference was statistically significant $(\mathrm{p}<0.000)$. Total hospital stay was significantly longer in the VH group (7.1days) when compared to the LAVH group (4.9days) and the difference was found to be statistically significant $(\mathrm{p}<0.000)$. There were no intraoperative complications noted in both the groups. There was no significant difference in the minor postoperative complications (fever and spotting per vaginum) between the two groups.

Conclusions: This study shows lesser operative time in VH group when compared to LAVH group and there is no added advantage in performing LAVH other than shorter hospital stay. Hence it is concluded that whenever feasible $\mathrm{VH}$ should be the preferred route of hysterectomy.

Keywords: Benign uterine disease, Laparoscopically assisted vaginal hysterectomy, LAVH vs. VH, Vaginal hysterectomy

\section{INTRODUCTION}

Hysterectomy is the most commonly performed gynaecological procedure. ${ }^{1}$ About $70 \%$ of hysterectomies are performed for benign conditions such as fibroid uterus, uterine prolapse, adenomyosis, dysfunctional uterine bleeding etc. Hysterectomy can be done by abdominal, vaginal or laparoscopic approach.
Based on the indications for surgery, surgeon's training and preference, uterine size, presence or absence of associated pelvic pathologies and patient's choice, the surgical route of approach is decided. Traditional vaginal hysterectomy $(\mathrm{VH})$ is commonly preferred in patients with uterine size equivalent to or less than 12 weeks gestation, no history of previous surgery, normal adnexa and absence of associated pelvic pathologies. Nowadays, with advances in laparoscopic techniques, laparoscopic 
assisted vaginal hysterectomies (LAVH) are done in increasing number for benign uterine disease.

Few studies compared the abdominal and vaginal route of hysterectomy and concluded that both operation and recovery time is shorter in vaginal route than the abdominal route..$^{2-4}$ Few studies found that laparoscopic assisted hysterectomies have advantages of lesser postoperative pain and shorter hospital stay than abdominal hysterectomies. ${ }^{5,6}$ Only few studies compared the less invasive techniques LAVH and VH. Furthermore, nowadays there is a trend in favour of LAVH even for patients in whom $\mathrm{VH}$ is feasible. Hence, this study is undertaken to compare the efficacy of LAVH and the traditional vaginal hysterectomy for the treatment of benign uterine disease and also to find out the advantage of LAVH over VH.

\section{METHODS}

A retrospective observational study was conducted from January 2015 to December 2015 in a tertiary care hospital: Shri Sathya Sai Medical College and Research Institute. The study population consists of patients who had undergone hysterectomy for benign uterine disease excluding prolapse of uterus. Medical records of patients who had undergone vaginal hysterectomy (50) and LAVH (50) without any medical illness and without previous surgical history (except sterilisation) were collected. The documentation in those 100 case sheets was reviewed. Age, parity, indication for hysterectomy, operative time (from the time of incision to the placement of last suture), intra operative and postoperative complications and duration of hospital stay were noted and compared between the two groups.

In all patients, documentation included following aspects: complete history including previous surgeries, medical illness etc., clinical examination to assess the size of uterus and its mobility, Ultrasound examination to assess the size of uterus and adnexa and pre-operative fractional curettage in indicated cases with histopathology reports. $\mathrm{VH}$ was performed under regional anaesthesia and LAVH under general anaesthesia.

\section{Operative techniques}

\section{Vaginal Hysterectomy (VH)}

A circumferential circular incision was made at cervico vaginal junction. Vaginal flaps were raised. Anteriorly, vesico uterine space and posteriorly pouch of Douglas were opened. The following structures were clamped, cut and ligated in sequence; Bilateral mackenrodt's ligaments, uterine vessels and cornuofundal structures. After checking haemostasis, vault closure was done with continuous sutures after fixing vault with bilateral mackenrodt's ligaments.

\section{Laparoscopically Assisted Vaginal Hysterectomy (LAVH)}

After creating pneumo peritoneum using verre's needle, four trocars were introduced. One for laparoscope and the other three for laparoscopic instruments. Vaginally manipulator was introduced into the uterus to manipulate the uterus. Bipolar cautery and scissors were used. Coagulation and cutting of bilateral cornuofundal structures (round ligament, ovarian ligament and fallopian tube) were done. Opening of the bladder flap and bladder dissection was done. Vaginally, circular incision was made at cervicovaginal junction. Pouch of Douglas was opened. Bilateral mackenrodt's ligaments and uterine vessels were clamped, cut and ligated. Uterus was removed vaginally and vault closure was done. At last, haemostasis was checked by re-evaluating the abdomen and pelvis through the laparoscope.

\section{Statistical analysis}

The data was analysed using SPSS version 23. Descriptive statistics was used to analyse the parity, indication and post-operative complications. Unpaired ttest was used for age, operative time and hospital stay.

\section{RESULTS}

On comparing the age of the patients, there was no gross difference in the mean age between the two groups ( $\mathrm{VH}$ 44.5years Vs. LAVH 45.36years). 45 (90\%) patients in $\mathrm{VH}$ and 48 (96\%) patients in LAVH were multiparous. Only $5(10 \%)$ patients in $\mathrm{VH}$ and $2(4 \%)$ patients in LAVH were nulliparous.

DUB (44\%) was the most common indication in $\mathrm{VH}$ group. DUB (28\%) and fibroid uterus (30\%) were the common indications in LAVH group. Fibroid accounted for only $20 \%$ of cases in $\mathrm{VH}$ group. Adenomyosis accounted for $20 \%$ of cases in LAVH group and only for $12 \%$ in $\mathrm{VH}$ group. The less common indications were cervical intraepithelial neoplasia III, Postmenopausal bleeding and endometrial hyperplasia.

The mean operative time was significantly shorter in the VH group (83.7 min) than in the LAVH group (128.7 min) and the difference was statistically significant $(p<0.000)$. Total hospital stay was significantly longer in the VH group (7.1 days) when compared to the LAVH group (4.9days) and the difference was found to be statistically significant $(<0.000)$.

\section{Table 1: Comparison of age of patients between $\mathrm{VH}$ and LAVH groups.}

\begin{tabular}{|ll|}
\hline Groups & Age of patients (years) Mean \pm SD* \\
\hline VH & $44.50 \pm 2.17$ \\
\hline LAVH & $45.36 \pm 2.24$ \\
\hline
\end{tabular}

SD*-Standard deviation 
Table 2: Comparison of parity of patients between $\mathrm{VH}$ and LAVH groups.

\begin{tabular}{|lll|}
\hline Groups & $\begin{array}{l}\text { Parity of patients } \\
\text { Multiparous } \\
\text { Number of } \\
\text { patients }(\%)\end{array}$ & $\begin{array}{l}\text { Nulliparous } \\
\text { Number of } \\
\text { patients }(\%)\end{array}$ \\
\hline VH & $45(90)$ & VH \\
\hline LAVH & $48(96)$ & LAVH \\
\hline
\end{tabular}

Table 3: Comparison of indications for hysterectomy between VH and LAVH groups.

\begin{tabular}{|lll|}
\hline Indications & $\begin{array}{l}\text { VH } \\
\text { Number of } \\
\text { patients (\%) }\end{array}$ & $\begin{array}{l}\text { LA Vumber of } \\
\text { patients (\%) }\end{array}$ \\
\hline $\begin{array}{l}\text { Dysfunctional } \\
\text { uterine bleeding }\end{array}$ & $22(44)$ & $14(28)$ \\
\hline Fibroid & $10(20)$ & $15(30)$ \\
\hline $\begin{array}{l}\text { Cervical } \\
\text { intraepithelial } \\
\text { neoplasia III }\end{array}$ & $3(6)$ & $2(4)$ \\
\hline $\begin{array}{l}\text { Post-menopausal } \\
\text { bleeding }\end{array}$ & $2(4)$ & $2(4)$ \\
\hline $\begin{array}{l}\text { Endometrial } \\
\text { hyperplasia }\end{array}$ & $7(14)$ & $7(14)$ \\
\hline Adenomyosis & $6(12)$ & $10(20)$ \\
\hline
\end{tabular}

Table 4: Comparison of operative time and hospital stay between VH and LAVH groups.

\begin{tabular}{|llll|}
\hline $\begin{array}{l}\text { Characteristics } \\
\text { Operative time } \\
\text { (minutes) }\end{array}$ & $83.70 \pm 16.31$ & $\begin{array}{l}128.70 \pm 15.9 \\
0\end{array}$ & 0.000 \\
$\begin{array}{l}\text { Mean } \pm \text { SD* } \\
\text { Hospital stay } \\
\text { (days) }\end{array}$ & $7.10 \pm 1.36$ & $4.90 \pm 1.07$ & 0.000 \\
Mean \pm SD* & & & \\
\hline
\end{tabular}

SD*-Standard deviation

Table 5: Comparison of postoperative complications between VH and LAVH groups.

\begin{tabular}{|lll|}
\hline $\begin{array}{l}\text { Post-operative } \\
\text { complications }\end{array}$ & $\begin{array}{l}\text { VH } \\
\text { Number of } \\
\text { patients }(\%)\end{array}$ & $\begin{array}{l}\text { LAVH } \\
\text { Number of } \\
\text { patients (\%) }\end{array}$ \\
\hline Nil & $45(90)$ & $46(92)$ \\
\hline Fever & $2(4)$ & $2(4)$ \\
\hline $\begin{array}{l}\text { Spotting per } \\
\text { vaginum }\end{array}$ & $3(6)$ & $2(4)$ \\
\hline
\end{tabular}

There were no intraoperative complications noted in both the groups. Post-operative complications noted in both the groups were fever (after 24 hours) and spotting per vaginum (after $3^{\text {rd }}$ day) which subsided after 3-4 days with antibiotics. Fever was noticed equally (4\%) in both the groups. Spotting per vaginum was noticed in $6 \%$ of cases in $\mathrm{VH}$ group and $4 \%$ of cases in LAVH group.
There was no significant difference in those minor postoperative complications between the two groups.

\section{DISCUSSION}

Vaginal hysterectomy and abdominal hysterectomy are the two conventional methods of hysterectomy for benign uterine disease used widely. Since the advent of LAVH in 1988 by Reich, the technique has been imbibed slowly by the general Gynaecologists, as an alternative route for hysterectomy. ${ }^{7}$ Nowadays, Gynaecologists prefer to use LAVH even in cases where $\mathrm{VH}$ is feasible. The advantages of LAVH over $\mathrm{VH}$ and vice versa were analysed by many researchers in their studies.

Drohonovsky et al compared vaginal hysterectomy, laparoscopically assisted vaginal hysterectomy, and total laparoscopic hysterectomy in women with benign uterine disease and concluded that $\mathrm{VH}$ had the shortest operating time and least drop in haemoglobin but higher rate of febrile complications. ${ }^{8}$

A meta-analysis was conducted by Yunhong Guo et al, to compare LAVH and $\mathrm{VH}$, they found that although the clinical outcomes of LAVH are comparable with those of $\mathrm{VH}, \mathrm{LAVH}$ is associated with prolonged operative time. They concluded vaginal hysterectomy as the preferred surgical approach in properly selected patients. ${ }^{9}$

Ewelina Litwinska et al compared VH and LAVH in women with symptomatic uterine myomas and concluded that the main advantages of LAVH over $\mathrm{VH}$ are the possibility to explore the abdomen and pelvis as well as performing a safe adnexectomy. This study also proved that $\mathrm{VH}$ was associated with the shortest operating time and low blood loss. ${ }^{10}$

Kovachev S compared the efficacy of LAVH and VH for benign diseases and lesions of the female genital system and concluded that $\mathrm{VH}$ is the surgical intervention of choice for removal of uterus with or without adnexa when compared to LAVH, with lesser operative time and lesser decline in haemoglobin. They also stated that $\mathrm{LAVH}$ is preferable to $\mathrm{VH}$ only in cases of ovarian tumours and women with small pelvis. ${ }^{11}$

As proved by earlier studies, in our study also $\mathrm{VH}$ is associated with lesser operative time $(83.7 \mathrm{~min})$ when compared to LAVH (128.7min) and this difference is statistically significant ( $\mathrm{p}$ value $<0.000$ ).

Meta-analysis of 5 studies showed no significant difference in hospital stay between LAVH and VH. But in our study, there is significant difference in hospital stay between the two groups (VH-7.1 days, LAVH-4.9 days, p value $<0.000){ }^{9}$

This retrospective study has some limitations. The intraoperative blood loss or the postoperative drop in haemoglobin in both the groups could not be compared as 
the information available in the records was inadequate. Postoperative pain scoring and recovery time after surgery in both the groups could not be analysed due to insufficient data in the records.

\section{CONCLUSION}

As in earlier studies, this study also shows lesser operative time in $\mathrm{VH}$ group when compared to LAVH group. This study shows that there is no added advantage in performing LAVH other than shorter hospital stay. Intraoperative and postoperative complications are comparable in both the groups. Hence it is concluded that whenever feasible $\mathrm{VH}$ should be the preferred route of hysterectomy. LAVH should be restricted to those cases where adnexectomy is indicated or where technical difficulties in $\mathrm{VH}$ due to big uterine size or adhesions are expected.

Funding: No funding sources Conflict of interest: None declared

Ethical approval: The study was approved by the Institutional Ethics Committee

\section{REFERENCES}

1. Wu JM, Wechter ME, Geller EJ, Nguyen TV, Visco AG. Hysterectomy Rates in the United States, 2003. Obstet Gynecol. 2007;110:1091-5.

2. Benassi L, Rossi T, Kaihura CT. Abdominal or vaginal hysterectomy for enlarged uteri: a randomized clinical trial. Am J Obstet Gynecol. 2002;187:1561-5.

3. Taylor SM, Romero AA, Kammerer-Doak DN. Abdominal hysterectomy for enlarged myomatous uterus compared with vaginal hysterectomy with morcellation. Am J Obstet Gynecol. 2003;189:157983.

4. Harmanli OH, Gentzler CK, Byun S. A comparison of abdominal and vaginal hysterectomy for the large uterus. Int J Gynaecol Obstet. 2004;87:19-23.

5. Hwang JL, Seow KM, Tsai YL. Comparative study of vaginal, laparoscopically assisted vaginal and abdominal hysterectomies for uterine myoma larger than $6 \mathrm{~cm}$ in diameter or uterus weighting at least $450 \mathrm{~g}$ : a prospective randomized study. Acta Obstet Gynecol Scand. 2002;81:1132-38.

6. Garry R, Fountain J, Mason S. The evaluate study: two parallel randomised trials one comparing laparoscopic with abdominal hysterectomy, the other comparing laparoscopic with abdominal hysterectomy, the other comparing laparoscopic with vaginal hysterectomy. BMJ. 2004;328:129-36.

7. Reich H, De Caprio J, McGlynn F. Laparoscopic Hysterectomy. J Gynecol Surg.1989;5:213-6.

8. Drahonovsky J, Haakova L, Otcenasek M, Krofta L, Kucera E, Feyereis J. A prospective randomized comparison of vaginal hysterectomy laparoscopically assisted vaginal hysterectomy and total laparoscopic hysterectomy in women with benign uterine disease. Eur J Obstet Gynecol Reprod Biol. 2010;148(2):1726.

9. Guo Y, Tian X, Wang L. Laparoscopically-Assisted Vaginal Hysterectomy vs. Vaginal Hysterectomy: Meta-Analysis the journal of minimally invasive gynecology. 2013;20(1):15-21.

10. Litwińska E, Nowak M, Kolasa-Zwierzchowska D, Nowińska-Serwach A, Władziński J, Szpakowski A, et al. Vaginal hysterectomy vs. laparoscopically assisted vaginal hysterectomy in women with symptomatic uterine leiomyomas: a retrospective study. Prz Menopauzalny. 2014;13(4):242-6.

11. Kovachev S, Ganovska A, Stankova T. Comparison of Laparoscopic Assisted Vaginal Hysterectomy and Vaginal Hysterectomy for Benign Diseases and Lesions of the Female Genital System Akush Gi. nekol. 2016;55(1):4-10.

Cite this article as: Sathiyakala R, Srinivasan S, Karnaboopathy R. Comparison of vaginal hysterectomy and laparoscopically assisted vaginal hysterectomy in women with benign uterine disease: a retrospective study. Int $\mathbf{J}$ Reprod Contracept Obstet Gynecol 2016;5:3915-8. 